University of New Hampshire

University of New Hampshire Scholars' Repository

Applied Engineering and Sciences Scholarship

Applied Engineering and Sciences

10-20-2011

\title{
Free and open source software in computing education
}

\author{
Stephen Jacobs \\ Rochester Institute of Technology \\ Clif Kussmaul \\ Muhlenberg College \\ Mihaela C. Sabin \\ University of New Hampshire, Manchester, mihaela.sabin@unh.edu
}

Follow this and additional works at: https://scholars.unh.edu/unhmcis_facpub Comments

(C) 2011, Association for Computing Machinery, Inc. This is the author's version of the work. It is posted here for your personal use. Not for redistribution. The definitive Version of Record was published in Proceedings of the 2011 conference on Information technology education, https://dx.doi.org/10.1145/2047594.2047606.

\section{Recommended Citation}

Stephen Jacobs, Clif Kussmaul, and Mihaela Sabin, Free and open source software in computing education, Proceedings of the 2011 Conference on Information Technology Education (New York, NY, USA), SIGITE '11, ACM, 2011, pp. 41-42.

This Article is brought to you for free and open access by the Applied Engineering and Sciences at University of New Hampshire Scholars' Repository. It has been accepted for inclusion in Applied Engineering and Sciences Scholarship by an authorized administrator of University of New Hampshire Scholars' Repository. For more information, please contact Scholarly.Communication@unh.edu. 


\section{Free and Open Source Software in Computing Education}

\author{
Stephen Jacobs \\ Interactive Games and Media \\ Rochester Institute of Technology \\ Rochester, New York, USA \\ sj@mail.rit.edu
}

\author{
Clif Kussmaul \\ Mathematics and Computer Science \\ Muhlenberg College \\ Allentown, Pennsylvania, USA \\ kussmaul@muhlenberg.edu
}

\author{
Mihaela Sabin (moderator) \\ Division of Science and Technology \\ University of New Hampshire \\ Manchester, New Hampshire, USA \\ mihaela.sabin@unh.edu
}

\begin{abstract}
Free and Open Source Software (FOSS) exemplifies the merit and successes of open content, understood broadly as creative work that explicitly allows sharing and further changes by anyone, whether an individual or organization. Although the benefits of improving computing education with open source practices are largely acknowledged, transforming teaching to create effective learning environments has many challenges. The panelists will bring different perspectives on teaching strategies and curricular content they have used in their classrooms. These perspectives will exemplify key issues with FOSS-based education and FOSSbased IT systems. The developer and user communities established around FOSS-based IT systems are of particular interest to the IT discipline because of its focus on user centeredness and advocacy for advancing professional practices in authentic environments.
\end{abstract}

\section{Categories and Subject Descriptors}

K.3.2 [Computer and Information Science Education]: Computer science education, Curriculum.

\section{General Terms}

Experimentation, Human Factors, Languages, Legal Aspects, Management.

\section{Keywords}

Free and open source software, IT system development, collaboration.

\section{INTRODUCTION}

The panel reports on different experiences with integrating Free and Open Source Software (FOSS) development in computing curricula at three schools: Rochester Institute of Technology (RIT), Muhlenberg College, and University of New Hampshire (UNH). Two of the panelists teach in the Information Technology discipline, but in two different academic settings: Stephen Jacobs is an Associate Professor in the School of Interactive Games and Media in the College of Computing and Information Sciences at RIT; Mihaela Sabin is an Associate Professor in the Computer Information Systems Program in the Division of Science and Technology at UNH. The third panelist, Clif Kussmaul, is an Associate Professor in Computer Science and teaches in the Mathematics and Computer Science Department at Muhlenberg College.

The motivation for this panel stems from the following factors:

- There is evidence of the impact of FOSS on economic development [1].

Copyright is held by the author/owner(s).

SIGITE'11, October 20-22, 2011, West Point New York, USA.

ACM 978-1-4503-0863-2/11/09.
- Computing curricula have adopted FOSS to improve learning opportunities that emphasize collaboration and problem solving applied to authentic, real-world experiences $[2,3]$

- Other curricular connections with FOSS are around service learning $[4,5,6]$.

- Software providers have created community service programs to engage and prepare students and faculty to contribute free and open source software [7,8].

The benefits of improving computing education with open source practices are largely acknowledged. However, transforming teaching by adopting FOSS principles and practices to create effective learning environments has many challenges. The panelists will bring different perspectives on teaching strategies and curricular content they have used in their classrooms. These perspectives will exemplify key issues with FOSS-based education: types and scope of projects students get involved with; infrastructure resources and expertise needed to carry out these projects; learning outcomes and assessment measures; and limitations and barriers experienced with various teaching approaches.

\section{THE PANELISTS}

Stephen Jacobs began applied research and community work in FOSS by creating a seminar course in educational game development for the One Laptop per Child XO/Sugar (OLPCS) computing platform [9] in 2009. His approach to involving students is to introduce them to FOSS processes via a "Humanitarian Free and Open Source Software Development" course and then to assist them in continuing those projects beyond the initial class. This has led to a community centered around FOSS at RIT consisting of students, alumni, staff and faculty.

A wide variety of Humanitarian FOSS projects (HFOSS), on and off OLPCS, have been created or continued in independent studies, co-ops, on-campus jobs and Summer Undergraduate Research Fellowships. He encourages faculty to create courses and experiences that can be open to a wide range of students.

Clif Kussmaul has contributed to and provided consulting using FOSS such as Drupal and TWiki. He has also supervised a variety of student projects using or extending FOSS, including Drupal, Moodle, and SubjectsPlus. His current approaches to involving students are also based on how the roles of FOSS participants change over time [10]. Thus, he recommends a use-study-addbuild-leverage (USABL) model [11], in which students first use and study FOSS, then make minor additions, and finally build larger components or leverage FOSS to solve other problems.

There is a perception that FOSS requires significant experience with programming and specialized tools. Although useful, such experience is not required. Thus, Clif and collaborators are 
working to identify and document ways for students and teachers from a broad range of backgrounds to participate in FOSS.

Mihaela Sabin coordinates the Humanitarian Free Open Source Software (HFOSS) Chapter at the University of New Hampshire. The project started three years ago when four community partners formulated their IT needs to students in two courses [12]. Since then, the Computer Information Systems program at University of New Hampshire in Manchester (UNHM) has built partnerships with eleven local nonprofits, state agencies, and small businesses to enrich curricula of four courses with real-world projects and engaged over 150 students who participated in 36 project teams [13].

Incorporating HFOSS activities in CIS courses has many advantages: participants are motivated to take on higher challenges; project activities are inclusive of diverse academic abilities, cultural backgrounds, and life experiences; communication and collaboration are enhanced by FOSS means (version control, wikis, forums, and IRC text messaging); and partnerships cross institutional and geographical boundaries. One challenge, however, stands out.

There is a visible polarization between design activities and implementation activities. Students themselves feel that one either loves programming or hates it. To "depolarize" implementation activities from the other software development activities, the HFOSS projects themselves become a learning resource that students author, whether they create, critique, or revise system documents, models, or source code.

\section{REFERENCES}

[1] Lerner, J. and Schankerman, M. (2010). The Comingled Code: Open Source and Economic Development. Boston, MA: The MIT Press.

[2] Dionisio, J.D.N., Dickson, C.L., August, S.E., Dorin, P.M., and Toal, R. (2007). "An open source software culture in the undergraduate computer science curriculum." Inroads - The SIGCSE Bulletin. 39(2), June 2007.

[3] Gehringer, E.F. (2007). "Open source for homework: Real projects, peer reviewed." Proceedings of the $38^{\text {th }}$ SIGCSE Technical Symposium on Computer Science Education, Covington, KY, March 2007.
[4] The Humanitarian Free and Open Source Software Project: Building Free Open Source Software for Society (2011). Retrieved May 19, 2011, from http://www.hfFOSS.org.

[5] Morelli, R.A., Tucker, A., Danner, N., de Lanerolle, T., Ellis, H.J.C., Izmirli, O., Krizanc, D., and Parker, G. (2009). "Revitalizing computing education by building free and open source software for humanity." Communications of the ACM. 52(8), 67-75. August.

[6] Jacobs, S. (2010). "Building an education ecology on serious game design and development for the One Laptop Per Child and Sugar platforms: A service learning course builds a base for peer mentoring, Cooperative Education internships and sponsored research." Proceedings of the 3rd IEEE Games Innovation Conference, Honk Kong, 2010.

[7] Professors' Open Source Summer Experience (2011). Red Hat sponsored faculty workshop series. Retrieved May 19, 2011, from http://teachingopensource.org/index.php/PFOSSE.

[8] Google Summer of Code (2011). Global program supporting students to write code for open source projects. Retrieved May 19, 2011, from http://code.google.com/soc/.

[9] Sugar Labs (2011). Software provider to the One Laptop Per Child (OLPC). Retrieved May 19, 2011, from http://sugarlabs.org.

[10] Jensen, C., and Scacchi, W. (2007). Role migration and advancement processes in FOSSD projects: A comparative case study. Proceedings of the 29th International Conference on Software Engineering (ICSE’07), 364-374. Minneapolis, MN: IEEE Computer Society.

[11] Kussmaul, C. "Software projects using free and open source software". Proceedings of the American Society for Engineering Education Annual Conference, Austin, TX.

[12] Sabin, M. (2008). "A Collaborative and Experiential Learning Model Centered around Real-World Projects." Proceedings of the $9^{\text {th }}$ SIGITE Information Technology Education Conference, Cincinnati, OH, October 2008.

[13] Sabin, M. (2011). "Towards Successful Client-Oriented HFFOSS Projects." The $3^{\text {rd }}$ annual Humanitarian FFOSS Education Symposium, jointly with SIGCSE 2011, Dallas, TX, March 2011. 